\title{
Increased Risk of Musculoskeletal Disorders and Mental Health Problems in Retired Professional Jockeys: A Cross-Sectional Study
}

\section{()(1)}

\section{Authors}

Anna-Louise Mackinnon'1, Kate Jackson¹, Kerry Kuznik', 2, Alison Turner¹, Jerry Hill², Madeleine A. M. Davies ${ }^{3,4}$, Mary Elizabeth Jones ${ }^{5}$, Antonella Delmestri ${ }^{1,3}$, Maria T. Sanchez-Santos ${ }^{1,3}$, Julia Newton ${ }^{1,3}$

\section{Affiliations}

1 Nuffield Department of Orthopaedics, Rheumatology and Musculoskeletal Sciences, University of Oxford, Arthritis Research UK Centre for Sport, Exercise and Osteoarthritis, Oxford, United Kingdom of Great Britain and Northern Ireland

2 British Horseracing Authority Ltd, Medical, London, United Kingdom of Great Britain and Northern Ireland

3 Nuffield Department of Orthopaedics, Rheumatology and Musculoskeletal Sciences, University of Oxford, Oxford, United Kingdom of Great Britain and Northern Ireland

4 Department of Health, University of Bath, Bath, United Kingdom of Great Britain and Northern Ireland

5 Department of Primary Care and Population Health, Institute of Epidemiology and Health Care, University College London, London, United Kingdom of Great Britain and Northern Ireland

Key words osteoarthritis, osteoporosis, anxiety, depression, athlete, chronic disease

accepted 25.04.2019

\section{Bibliography}

DOI https://doi.org/10.1055/a-0902-8601

Published online: 7.8.2019

Int J Sports Med 2019; 40: 732-738

(c) Georg Thieme Verlag KG Stuttgart · New York

ISSN 0172-4622

\section{Correspondence}

Dr. Anna-Louise Mackinnon

Nuffield Department of Orthopaedics, Rheumatology and Musculoskeletal Sciences,

University of Oxford, Arthritis Research UK Centre for Sport, Exercise and Osteoarthritis,

Botnar Research Centre,

OX3 7LD Oxford,

United Kingdom of Great Britain and Northern Ireland,

Tel.: + 353/777/0237 937, Fax: + 353/186/5223 407

almackinnon@icloud.com

\section{ABSTRACT}

To examine the prevalence of chronic disease and mental health problems in retired professional, male jockeys compared to an age-matched reference population. A cross-sectional study comparing data from a cohort of retired professional jockeys with an age-matched general population sample. Male participants (age range: $50-89$ years old) were used to compare health outcomes of self-reported physician-diagnosed conditions: heart disease, stroke, diabetes, hypertension, osteoporosis, osteoarthritis, depression and anxiety between study populations. Conditional logistic regression models were used to estimate associations between study groups and health outcome. In total, 810 participants (135 retired professional male jockeys and 675 participants from the reference population) were included, with an average age of $64.7 \pm 9.9$ years old. Increased odds of having osteoporosis (OR $=6.5,95 \% \mathrm{Cl} 2.1$ $20.5)$, osteoarthritis $(\mathrm{OR}=7.5,95 \% \mathrm{Cl} 4.6-12.2)$, anxiety $(\mathrm{OR}=2.8,95 \% \mathrm{Cl} 1.3-5.9)$ and depression $(\mathrm{OR}=2.6,95 \% \mathrm{Cl}$ $1.3-5.7$ ) were seen in the retired professional jockeys. No differences were found for the remaining health outcomes. Retired professional jockeys had increased odds of musculoskeletal disease and mental health problems compared to the general population. Understanding the prevalence of chronic disease and mental health problems in retired professional jockeys will help inform screening and intervention strategies for jockeys. 


\section{Introduction}

The beneficial effects of exercise on chronic disease have been well documented, with significantly reduced mortality due to cardiovascular disease, hypertension, diabetes and cancer [1,2]. Regular exercise has also been shown to have positive effects on mental health in the general population [3,4]; however, it is known that professional athletes may be subject to unique stresses, such as when injured or underperforming, which may increase their predisposition to mental health problems [5].

The prevalence of osteoarthritis (OA) in the general population ranges from $12.3-21.6 \%$ with risk factors including older age, female sex, obesity, genetic predisposition, dietary factors and jointspecific factors including injury, malalignment and abnormal loading $[6,7]$. In some former professional sports participants, the prevalence of musculoskeletal problems is higher compared to the general population, particularly OA of the lower limb [8-10]. Sport injuries contribute to the development of $\mathrm{OA}$ and mental health problems in retired elite athletes $[8,11]$.

Horse-racing is a popular sport in the UK. There are currently over 400 licensed professional jockeys, over 350 amateur jockeys and over 5,000 stable staff. McCrory et al. reported a fall rate of $0.4 \%$ per ride for flat jockeys, $6.8 \%$ for jump jockeys and an injury incidence per fall of $39.8 \%$ for flat jockeys and $18.0 \%$ for jump jockeys in Britain between 1992 and 2001 [12]. A more recent Irish paper reported falls and injuries rates in Irish jump and flat racing between 2011 and 2015 [13]. Fall rates were of 3.8 and 49.5 falls per 1000 rides, and 352.8 and 203.8 injuries per 1000 falls for flat and jump jockeys, respectively.

It has been shown that exercise is important in obtaining peak bone mineral density and reducing the risk of osteoporosis [14]; however, in weight-restricted sports there is risk of presenting poor bone health [15]. There is one published paper investigating musculoskeletal health in 28 retired Irish jockeys, which did not identify an increase in osteoporosis compared to a reference group [16]. Participation in elite-level cricket and rugby has been shown to have a beneficial effect on cardiovascular disease $[17,18]$. There is only one paper referring to chronic disease in retired male jockeys and this paper was primarily researching physiological and health markers in 28 retired Irish jockeys [19]. In this cohort $14 \%$ reported having high blood pressure, $14 \%$ heart disease, $7 \%$ stroke, $11 \%$ impaired lung function and $4 \%$ kidney removal. To our knowledge, there have been no studies investigating chronic conditions in retired professional jockeys.

This study was designed to fill this gap in epidemiological research on this unique athlete population, aiming to improve knowledge on health status in retired professional jockeys. Thus, the overarching aims of this study were: 1 ) to describe the prevalence of chronic disease, including cardiovascular, musculoskeletal conditions and mental health problems in a cohort of retired male professional jockeys, and 2) to compare those with an age-matched sample from the general population.

\section{Materials and Methods}

\section{Study Design}

A standardised core questionnaire was designed and developed by the Arthritis Research UK Centre for Sport, Exercise and Osteoarthritis to investigate the health of retired elite athletes. The ques- tionnaire was comprised of a core set of questions including injury, medical and playing history as previously published $[17,18]$. This questionnaire was further adapted for horseracing with the involvement of current and retired jockeys and stakeholder organisations from racing including the British Horseracing Authority (BHA), The Racing Foundation, British Racing School (BRS), Professional Jockeys Association (PJA), National Association of Racing Staff (NARS), Racehorse Owners Association (ROA), Racing Welfare (RW) Injured Jockeys Fund (IJF), Jockeys Education and Training Scheme (JETS), Northern Racing College (NRC) and National Trainers Federation (NTF). Two further public participation (PPI) groups were then undertaken. The first group comprised of 4 retired and current jockeys and 4 researchers. The jockeys were asked to complete the questionnaire, any concerns, queries and difficulties were then discussed and recorded. The research team revised the questionnaire taking into account the feedback. The second PPI group, comprising of 4 retired and current jockeys and 3 researchers, was then asked to review the revised questionnaire. Feedback was discussed and recorded and the questionnaire finalised.

The questionnaire was available online and in paper form. The paper version was distributed via mailouts from the PJA, BHA and JETS and IJF almoners. The online version was emailed to any retired jockeys contacting the research team as a result of social medial notifications, adverts on racecourses, adverts in industry newsletter and personal communications.

Data were collected and managed using REDCap (Research Electronic Data Capture) platform [20], hosted at the University of Oxford. REDCap is a secure web-based application designed to support data capture for research studies. Paper questionnaires were manually entered, whilst REDCap's survey tool was used for electronic questionnaire completion.

Ethics approval for The Retired Jockey Study was granted from the University of Oxford (R4403/RE002). The Study meets the ethical standards of the International Journal of Sports Medicine [21]. Data were anonymised and informed consent was obtained from all participants.

\section{Participants}

The Jockey Study

One overarching database of all retired professional jockeys does not exist within the racing industry; however, the PJA estimates that at least $95 \%$ of all GB licensed jockeys will have been members of the PJA during their racing career. The PJA 'badge holders' are retired professional jockeys who have been GB licensed professional jump jockeys for at least 10 seasons, or flat jockeys for at least 15 seasons. There were 230 PJA badge holders at the time of distribution of the questionnaires in 2016. This database was used as the primary data source, and was supplemented by contacting retired professional jockeys using additional databases, as described in the study design, held by BHA, JETS and the IJF.

\section{Comparison cohort}

The English Longitudinal Study of Ageing (ELSA) was used as a reference population representative of the general population [22]. The ELSA study is a prospective study of community-dwelling older people, which included individuals who were living within the household at the time of the Health Survey for England (HSE) in- 
terview. Wave 1 of ELSA was used in this study. Data were collected in 2002-2003 and a core sample of 11391 women and men aged 50 and over were recruited. Variables from Wave 0 of ELSA were used when they were not collected at Wave 1. Details of the measurement protocol can be found at http://www.ifs.org.uk/elsa

Male participants aged 50-89 years were included in the reference population ( $\triangleright$ Fig. 1). Every retired professional male jockey was matched individually by age with five male participants from the reference population (1:5).

\section{Outcome: Chronic conditions and mental disease}

Outcomes included seven self-reported, GP-diagnosed chronic conditions; heart problems, stroke, hypertension, diabetes, asthma, osteoporosis and $\mathrm{OA}$ and two mental health problems; lifetime depression and anxiety. Details regarding the harmonisation process of each health outcome have been described in detail previously $[17,18]$ (more details on measurements are available from the authors on request).

\section{Covariates}

Body mass index (BMI) (weight in kilograms divided by height in metres squared) was calculated from clinically measured weight and height in the reference population and from self-reported measurements in the retired professional jockeys. Smoking status was selfreported in both studies and categorised as 'current smoker' vs. 'non-smoker' (including ex-smokers).

\section{Statistical analysis}

All analyses were conducted using Stata Statistical Software: Release 15 (StataCorp, College Station, Texas). Characteristics for jockeys and the reference population were assessed using mean and standard deviation (SD) for continuous variables, and relative and absolute values for categorical variables. Conditional logistic regression was used to estimate the differences between jockeys and the reference population adjusting for BMI and smoking status. Prevalence odds ratio (OR) and their $95 \%$ confidence intervals $(\mathrm{Cl})$ were calculated, using the maximum number of individuals available for each health outcome. The level of significance was set at $\mathrm{p}<0.05$ for all statistical analyses.

\section{Results}

Of the 1464 questionnaires distributed online and by post as described in the study design, 260 were returned ( $>$ Fig. 1). After excluding duplicates, incomplete questionnaires and those completed by non-professional or female jockeys, a total of 209 questionnaires were available for analysis. The only response rate that could be calculated was for questionnaires distributed to PJA badge holders, as this was the only up-to-date accurate database. The response rate for this sub-group was $53 \%$ (122/230). A response rate for jockeys recruited from organisations other than the PJA could not be derived, as the number of jockeys who physically received the invitation to participate in the study cannot be determined due to inaccurate contact details, duplicate contacts and deceased jockeys.

There were 209 male professional jockeys, who returned completed questionnaires. Of these, 135 jockeys aged 50 + were included in the age-matched analysis alongside 675 participants from the reference population ( $\mathbf{F i g} \mathbf{1} \mathbf{1}$ ).

Demographic characteristics of all eligible retired professional jockeys, jockeys aged $50+$, and reference population are shown in

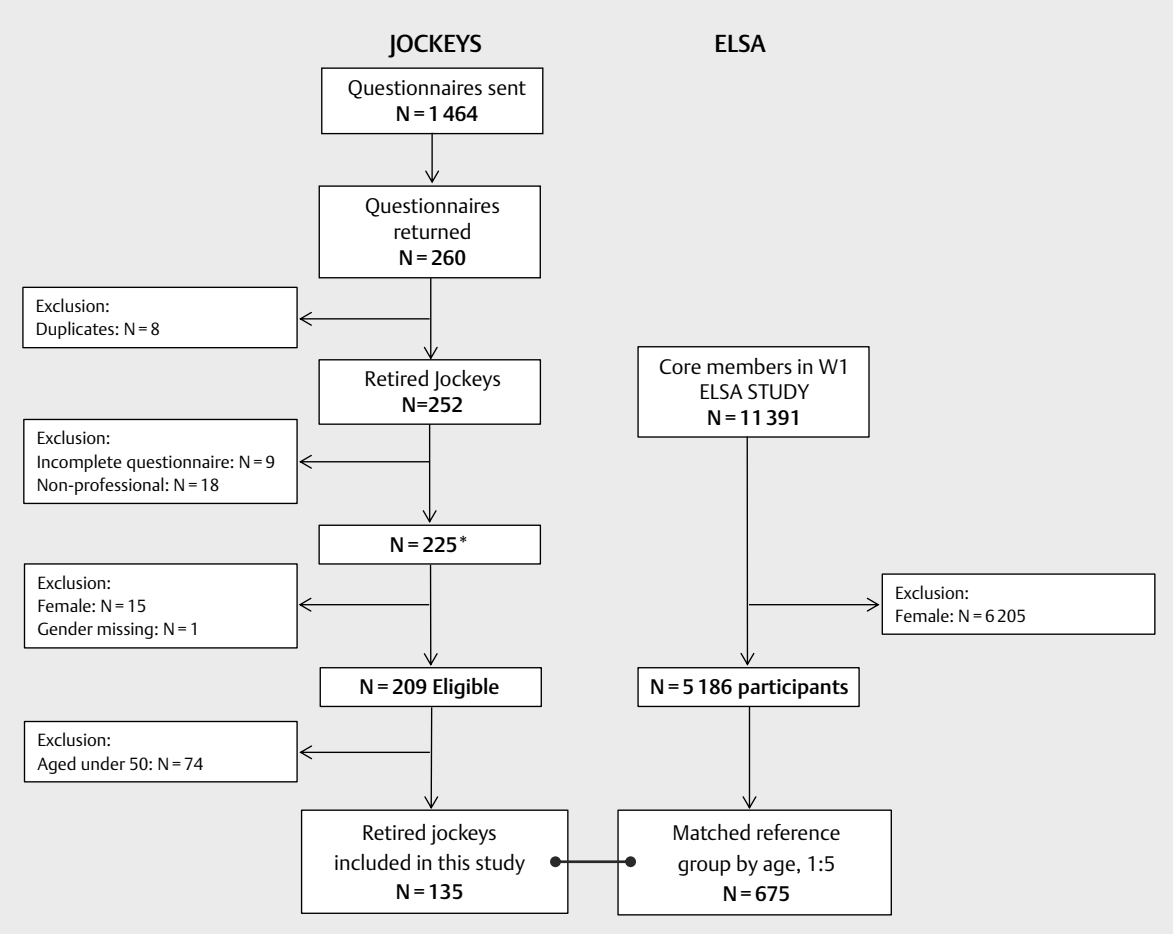

Fig. 1 Flowchart of the study. 
- Table 1 Characteristics of the retired, professional jockeys and reference population.

\begin{tabular}{|c|c|c|c|c|}
\hline Participant characteristics & All jockeys $(n=209)$ & Jockeys age $50+(n=135)$ & Reference population $(n=675)$ & p-value * \\
\hline Age (years), mean (SD) & $56.1(14.6)$ & $64.7(9.9)$ & $64.7(9.9)$ & \\
\hline Ethnicity, n (\%) & & & & 0.138 \\
\hline White & $195(93.3)$ & $122(90.4)$ & $650(96.3)$ & \\
\hline Mixed and Other & $9(4.3)$ & $8(5.9)$ & $23(3.4)$ & \\
\hline Missing & $5(2.4)$ & $5(3.7)$ & $2(0.3)$ & \\
\hline BMI $\left(\mathrm{kg} / \mathrm{m}^{2}\right)$, mean $(\mathrm{SD})$ & $24.5(2.9)$ & $25.0(3.0)$ & $27.4(3.8)$ & $<0.001$ \\
\hline BMI $\left(\mathrm{kg} / \mathrm{m}^{2}\right), \mathrm{n}(\%)$ & & & & $<0.001$ \\
\hline Under/Normal weight & $125(59.8)$ & $73(54.1)$ & $157(23.3)$ & \\
\hline Overweight/Obese & $72(34.5)$ & $57(42.2)$ & $451(66.8)$ & \\
\hline Missing & $12(5.7)$ & $5(3.7)$ & $67(9.9)$ & \\
\hline Smoking status, n (\%) & & & & 0.113 \\
\hline Non-smoker & $176(84.2)$ & $116(85.9)$ & $546(80.9)$ & \\
\hline Current smoker & $28(13.4)$ & $16(11.9)$ & $118(17.5)$ & \\
\hline Missing & $5(2.4)$ & $3(2.2)$ & $11(1.6)$ & \\
\hline \multicolumn{5}{|l|}{ Racing history } \\
\hline \multicolumn{5}{|l|}{ Type of race } \\
\hline Flat & $65(31.1)$ & $44(32.6)$ & - & \\
\hline Jump & $130(62.2)$ & $81(60.0)$ & - & \\
\hline Both & $14(6.7)$ & $10(7.4)$ & - & \\
\hline Years since retirement from riding, mean (SD) & $30.0(11.3)$ & $33.4(10.2)$ & - & \\
\hline
\end{tabular}

- Table 1. The average age of all eligible jockeys was $56.1 \pm 14.6$ years (range $22-88$ years) and $93.3 \%$ identified their ethnicity as white. They had retired from racing for $30 \pm 11$ years, and $71 \%$ had 11 seasons or more of riding at a professional level. Thirty-one percent had a career in flat racing, $62 \%$ in jump racing and $7 \%$ in both jump and flat racing. Ethnicity, BMI, smoking status and racing history between all eligible retired professional jockeys and those aged $50+$ were similar ( Table $\mathbf{1}$ ). The retired professional jockey population had statistically lower BMI than the reference population ( Table 1). The percentage of white ethnicity and current smokers did not differ between groups.

In the group of all eligible jockeys, the most prevalent health outcome was OA ( $40.7 \%$ ), followed by hypertension ( $27.8 \%$ ), asthma (14.8\%) and depression (12.9\%). The prevalence of the remaining health outcomes was $12 \%$ or lower ( $\triangleright$ Fig. 2 ).

The prevalence of osteoporosis and OA were significantly higher in retired professional jockeys aged 50 than in the reference population (7.4 vs. $1.6 \%$ and 46.7 vs. $14.5 \%$, respectively; p-value $\leq 0.001$ ). Retired professional jockeys aged $50+$ also showed a significantly greater lifetime prevalence of anxiety and depression compared with the reference population (11.1, vs. $4.2 \%$ and 12.6 vs. $5.0 \%$, respectively). No significant differences were found for any other conditions analysed ( $\triangleright$ Table 2 ).

After adjusting for BMI and smoking status, the OR for musculoskeletal and mental health outcomes remained significant ( $>$ Table 2). An increased odds of having osteoporosis (OR $=6.5$, $95 \% \mathrm{Cl} 2.1-20.5), \mathrm{OA}(\mathrm{OR}=7.5,95 \% \mathrm{Cl} 4.6-12.2)$, anxiety $(\mathrm{OR}=2.8$, $95 \% \mathrm{Cl} 1.3-5.9)$ and depression $(\mathrm{OR}=2.6,95 \% \mathrm{Cl} 1.3-5.7)$ was seen in the retired professional jockey population.

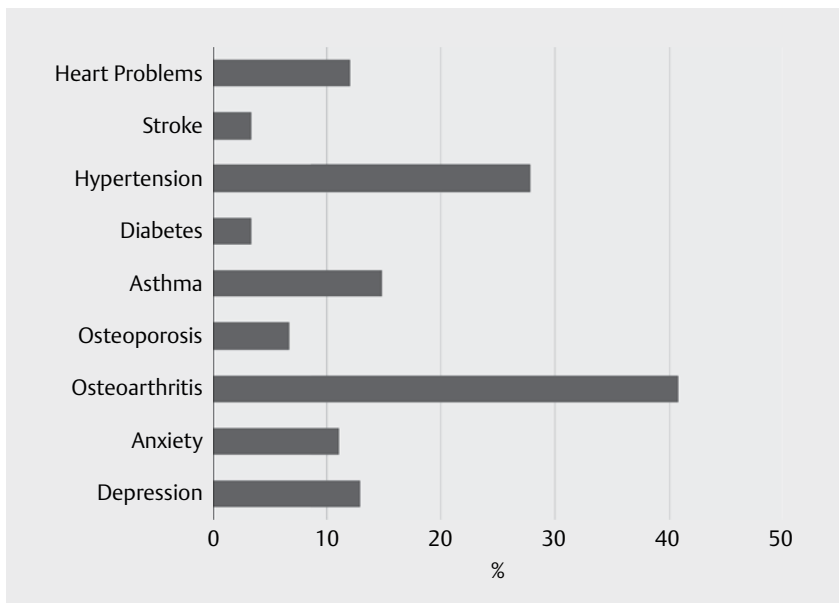

- Fig. 2 Prevalence of chronic diseases and mental health problems of all eligible retired professional jockeys.

\section{Discussion}

This study is the first to report the prevalence of chronic diseases and mental health problems in retired GB professional jockeys. Retired professional jockeys had a higher prevalence of musculoskeletal conditions and mental health problems compared with the reference population, which remained after adjusting for BMI and smoking.

This study has found that retired professional jockeys are at significantly increased odds of having osteoporosis in retirement with 
- Table 2 Prevalence and odds ratios (crude and adjusted) of chronic diseases and mental health problems in retired professional jockeys and reference population.

\begin{tabular}{|c|c|c|c|c|c|}
\hline Outcomes & Jockeys age $50+(n=135)$ & Reference population ( $n=675$ ) & $\mathbf{N}$ & Crude OR (95\% Cl) & Adjusted OR * $(95 \% \mathrm{Cl})$ \\
\hline \multicolumn{6}{|l|}{ Chronic condition } \\
\hline Heart problems, n (\%) & $23(17.0)$ & $159(23.6)$ & 729 & $0.68(0.41-1.12)$ & $0.81(0.48-1.37)$ \\
\hline Stroke, n (\%) & $7(5.2)$ & $30(4.4)$ & 728 & $1.35(0.55-3.31)$ & $1.20(0.48-3.04)$ \\
\hline Hypertension, n (\%) & $51(37.8)$ & $247(36.6)$ & 727 & $1.13(0.75-1.69)$ & $1.29(0.84-1.97)$ \\
\hline Diabetes, $\mathrm{n}(\%)$ & $7(5.2)$ & $57(8.4)$ & 728 & $0.62(0.27-1.40)$ & $1.07(0.44-2.60)$ \\
\hline Asthma, n (\%) & $20(14.8)$ & $70(10.4)$ & 727 & $1.54(0.88-2.70)$ & $1.72(0.95-3.14)$ \\
\hline Osteoporosis, n (\%) & $10(7.4)$ & $11(1.6)$ & 726 & $5.81(2.19-15.45)$ & $6.49(2.05-20.50)$ \\
\hline Osteoarthritis, n (\%) & $63(46.7)$ & $98(14.5)$ & 715 & $5.23(3.39-8.08)$ & $7.45(4.55-12.21)$ \\
\hline \multicolumn{6}{|c|}{ Mental health condition } \\
\hline Anxiety, n (\%) & $15(11.1)$ & $28(4.2)$ & 728 & $3.15(1.55-6.39)$ & $2.81(1.34-5.89)$ \\
\hline Depression, n (\%) & $17(12.6)$ & $34(5.0)$ & 727 & $2.79(1.47-5.28)$ & $2.60(1.33-5.07)$ \\
\hline
\end{tabular}

a prevalence of $7.4 \%$ and $\mathrm{OR}$ of $6.5(95 \% \mathrm{Cl} 2.1-20.5)$, after adjusting for BMI and smoking status. This result does not reflect the results of a previous retired jockey study, which found no difference in the bone mineral density (BMD) of 28 retired Irish jockeys compared to reference ranges [16]. This may be due to differing retired jockey populations, as the previous study had a narrow age range (50-70 years old); which is younger than this study population, and osteoporosis is known to be an age-associated morbidity. Jockeys are at risk of low energy consumption and poor weight management practices, which are thought to impact their ability to reach peak BMD [23-25]. In current newly-licensed jockeys in GB, Jackson et al. found $76 \%$ of male flat and $52 \%$ of male jump jockeys had low BMD (less than one SD below the average in the age-sex-reference) [15]. This result provides supporting evidence that low BMD persists into retirement ( $\triangleright$ Table $1 S$ ).

The prevalence of OA in retired professional jockeys over 50 years was $46.7 \%$ with an adjusted OR of 7.5 ( $95 \% \mathrm{Cl} 4.6-12.2)$. Two previous studies also found a higher prevalence of $\mathrm{OA}$ in retired professional rugby and cricket players compared to the general population, with an increased risk of 4.0 and 3.6-fold, respectively $[17,18]$. These consistent findings are likely to be a consequence of increased injury rates in former elite athletes. Injury has been reported as central to the development of lower limb OA in sporting populations [6,26], and injury is known to be prevalent in jockeys, which may suggest post-traumatic $\mathrm{OA}$ as the rationale for the higher prevalence reported in this study. Due to increased availability of routine healthcare provision there may be increased reporting in these populations in comparison with the general population ( $\triangleright$ Table 2S).

Our study also found a higher lifetime prevalence of self-reported, physician-diagnosed anxiety and depression compared to the reference population. A recent study by Losty et al. in 42 professional Irish jockeys has reported $57 \%$ exceeding the threshold for depression and $21.4 \%$ for generalised anxiety disorder when completing an online validated self-reported measurement tool [27]. There is great variability in the lifetime prevalence of depression and anxiety in the general population due to diverse collection and reporting methods. King et al., using a Composite International Di- agnostic Interview of general practice attendees in 6 European countries, reported previous 6 -month anxiety prevalence to be $8.4 \%$, and major depression to be $12.7 \%$ [28]. Kessler et al. reported the lifetime prevalence of anxiety and depression disorders as 28.8 and $16.6 \%$, respectively [29] using a face-to-face household survey of English speaking household residents in the USA. Compared to retired professional elite rugby and cricket cohorts, using the same reporting method, the lifetime prevalence of anxiety and depression was $6 \%$ and $5 \%$ respectively in rugby [17] and 12.4 and $8.8 \%$ respectively in cricket [18]. Therefore, whilst retired jockeys had significantly higher rates of anxiety and depression than the reference population, they appear to have similar rates to other retired athlete populations ( $\vee$ Table $3 \mathbf{3}$ ).

There are multiple possible contributing factors to the increased rates of anxiety and depression. The transition out of professional sport when athletes retire is associated with an increased risk of mental health problems including anxiety and depression [30]. There is an association between repeated mild traumatic brain injury and depression, which jockeys may have been exposed to during their riding career as a result of multiple falls [31]. Jockeys have been found to report depression 46 times more frequently if they have a current injury [27]. Racing is a weight-restricted sport and weight management practices may be associated with a higher risk of mental health problems during a racing career [32]. Pain and depression are recognised to frequently co-exist, with studies reporting increased rates of depression in patients with pain [33]. OA and career injuries may have increased pain in this population, in turn increasing the prevalence of mental health outcomes.

No differences were found in the prevalence of cardiovascular disease in retired professional jockeys compared to the reference population. Compared to previous studies of retired jockeys our study demonstrates a higher prevalence of hypertension (37.8) compared to the Cullen et al. study, with $14 \%$ of retired Irish jockeys reporting high blood pressure, but this may be explained by the increased mean age in our study [19]. In other sports, Davies et al. [17] found a significantly reduced prevalence of diabetes in retired rugby players and Jones et al. [18] found significantly reduced levels of heart problems in cricket players. This may be an indication 
of different physiological demands during elite sports participation, and the capacity of these demands to positively influence longer-term clinically relevant health outcomes.

\section{Strengths and limitations}

To our knowledge, this study is the first to investigate the prevalence of chronic diseases, such as cardiovascular and musculoskeletal diseases as well as lifetime mental health problems, in a retired professional jockey population. Furthermore, this study represents the largest, well-characterized cohort of retired professional jockeys. There was a high response rate for the PJA badge holders making this generalizable to more established jockeys with longer, more successful careers. However, this may be less generalizable to jockeys licenced for less than 10 years jump racing or 15 years flat racing.

Some potential limitations of this study include the exclusion of retired female jockeys so the findings may only be generalizable to retired professional male jockeys. There is a potential selection bias from those jockeys with chronic health problems being more likely to return a questionnaire regarding their health status. Alternatively, there may be a selection bias from jockeys who want to report positive health outcomes following a career in racing. As a cross-sectional study, it is not possible to investigate the cause of the higher prevalence of musculoskeletal diseases and lifetime depression and anxiety; therefore we cannot infer causality for these morbidities. Another limitation of this study included the self-reported height and weight in the retired professional jockey population compared to clinically measured BMI in the reference group. Previous studies that examined the accuracy of self-reported height and weight compared to measured values consistently reported that BMI tended to be underestimated [34, 35]. A recent study based on a sample of Irish ex-jockeys aged 50-70 [16] found that the average of measured BMI was $26.7 \mathrm{~kg} / \mathrm{m}^{2}$, around $1.7 \mathrm{~kg} / \mathrm{m}^{2}$ higher compared to our jockey population. Since the mean difference in BMI between the Irish ex-jockeys population and our reference population was smaller and non-statistically significant, we do believe that the impact of the self-reported BMI does not substantially influence on our findings. Information on physical activity and on duration, intensity or quantity of smoking was not available in both study populations. Those measures are potential confounders, which may influence musculoskeletal and mental health problem outcomes. Finally, whilst the data from ELSA Wave 1 is now 15 yrs old it is a comprehensive and relevant database available for comparison. The diagnosis of OA, osteoporosis, depression and anxiety has not changed significantly over the last 15 yrs so therefore the prevalence data should remain comparable to the retired professional jockeys. In addition, the survey questions used in ELSA were comparable to those used in our study.

\section{Conclusion}

Reported musculoskeletal diseases and mental health problems were significantly more prevalent in retired, male professional jockeys than in the reference population. No differences in the prevalence of cardiovascular diseases were found. Additional studies of female-only or mixed gender cohorts are needed to confirm the generalizability of these findings for female jockeys. Further re- search of the risk factors for increased musculoskeletal disease and mental health problems is required to identify potential interventions for current and future professional jockeys.

\section{Practical Implications}

- Osteoporosis is more common in retired professional jockeys than the general population. Educating young jockeys and addressing modifiable risk factors throughout their careers is important for their future bone health.

- These results confirm that the high incidence of low bone mineral density in newly-licensed jockeys is also present in the retired, professional jockey population.

- Strategies to improve safety and prevent injuries at racecourses and in training yards are required to reduce the risk of subsequent $\mathrm{OA}$ in both retired professional jockeys and racing staff.

- Mental health problems are prevalent in retired professional jockeys. Industry provision of mental health support during jockeys' careers, the transition into and during retirement is important.

\section{Acknowledgements}

Acknowledgements This research was supported by the British Horseracing Authority, the Professional Jockeys Association, Injured Jockey Fund and the Jockeys Education and Training Scheme. Funding This study was funded by the Racing Foundation (grant number HFR00920) and the Arthritis Research UK Centre for Sport, Exercise and Osteoarthritis. (Grant reference 21595). The Racing Foundation was represented on the steering group for this research but not directly involved in the research or preparation of the paper. Arthritis Research UK Centre for Sport, Exercise and Osteoarthritis had no involvement in the research other than financial.

\section{Conflict of Interest}

Authors declare that they have no conflict of interest.

\section{References}

[1] Reiner M, Niermann C, Jekauc D, Woll A. Long-term health benefits of physical activity-a systematic review of longitudinal studies. BMC Public Health 2013; 13: 813

[2] Warburton DE, Nicol CW, Bredin SS. Health benefits of physical activity: The evidence. CMAJ 2006; 174: 801-809

[3] Mead GE, Morley W, Campbell P, Greig CA, McMurdo M, Lawlor DA. Exercise for depression. Cochrane Database Syst Rev 2008; 4 : CD004366

[4] Rosenbaum S, Sherrington C. Is exercise effective in promoting mental well-being in older age? A systematic review. Br J Sports Med 2011; 45: $1079-1080$

[5] Rice SM, Purcell R, De Silva S, Mawren D, McGorry PD, Parker AG. The mental health of elite athletes: A narrative systematic review. Sports Med 2016; 46: 1333-1353

[6] Gelber AC, Hochberg MC, Mead LA, Wang NY, Wigley FM, Klag M]. Joint injury in young adults and risk for subsequent knee and hip osteoarthritis. Ann Intern Med 2000; 133: 321-328 
[7] Palazzo C, Nguyen C, Lefevre-Colau MM, Rannou F, Poiraudeau S. Risk factors and burden of osteoarthritis. Ann Phys Rehabil Med 2016; 59: $134-138$

[8] Gouttebarge V, Inklaar H, Backx F, Kerkhoffs G. Prevalence of osteoarthritis in former elite athletes: A systematic overview of the recent literature. Rheumatol Int 2015; 35: 405-418

[9] Kujala UM, Kaprio J, Sarna S. Osteoarthritis of weight bearing joints of lower limbs in former elite male athletes. BMJ 1994; 308: 231-234

[10] Molloy MG, Molloy CB. Contact sport and osteoarthritis. Br J Sports Med 2011; 45: 275-277

[11] Rice SM, Parker AG, Rosenbaum S, Bailey A, Mawren D, Purcell R. Sport-related concussion and mental health outcomes in elite athletes: A systematic review. Sports Med 2018; 48: 447-465

[12] McCrory P, Turner M, LeMasson B, Bodere C, Allemandou A. An analysis of injuries resulting from professional horse racing in France during 1991-2001: A comparison with injuries resulting from professional horse racing in Great Britain during 1992-2001. Br J Sports Med 2006; 40: 614-618

[13] O'Connor S, Warrington G, McGoldrick A, Cullen S. Epidemiology of injury due to race-day jockey falls in professional flat and jump horse racing in Ireland, 2011-2015. J Athl Train 2017; 52: 1140-1146

[14] Mountjoy M, Sundgot-Borgen J, Burke L, Carter S, Constantini N, Lebrun C, Meyer N, Sherman R, Steffen K, Budgett R, Ljungqvist A. The IOC consensus statement: beyond the female athlete triad-relative energy deficiency in sport (RED-S). Br J Sports Med 2014; 48: 491-497

[15] Jackson KA, Sanchez-Santos MT, MacKinnon AL, Turner A, Kuznik K, Ellis S, Box C, Hill J, Javaid MK, Cooper C, Arden NK, Newton JL. Bone density and body composition in newly licenced professional jockeys. Osteoporos Int 2017; 28: 2675-2682

[16] Cullen S, Donohoe A, McGoldrick A, McCaffrey N, Davenport C, Byrne B, Donaghy C, Tormey W, Smith D, Warrington G. Musculoskeletal health, kidney and liver function in retired jockeys. Int I Sports Med 2015; 36: 968-973

[17] Davies MAM ADJ, Delmestri A, PTK S, Stokes KA, Arden NK, Newton JL. Health amongst former rugby union players: A cross-sectional study of morbidity and health-related quality of life. Sci Rep 2017; 7: 11786

[18] Jones ME, Davies MAM, Leyland KM, Delmestri A, Porter A, Ratcliffe J, Peirce N, Newton JL, Arden NK. Osteoarthritis and other long-term health conditions in former elite cricketers. J Sci Med Sport 2018; 21: 558-563

[19] Cullen S, Donohoe A, McGoldrick A, McCaffrey N, Davenport C, Byrne B, Donaghy C, Tormey W, Smith D, Warrington G. Physiological and health characteristics of ex-jockeys. J Sci Med Sport 2016; 19: 283-287

[20] Harris PA, Taylor R, Thielke R, Payne J, Gonzalez N, Conde JG. Research electronic data capture (REDCap)-a metadata-driven methodology and workflow process for providing translational research informatics support. J Biomed Inform 2009; 42: 377-381

[21] Harriss DJ, Macsween A, Atkinson G. Standards for ethics in sport and exercise science research: 2018 update. Int J Sports Med 2017; 38: $1126-1131$
[22] Steptoe A, Breeze E, Banks ], Nazroo J. Cohort profile: The English longitudinal study of ageing. Int J Epidemiol 2013; 42: 1640-1648

[23] Dolan E, McGoldrick A, Davenport C, Kelleher G, Byrne B, Tormey W, Smith D, Warrington GD. An altered hormonal profile and elevated rate of bone loss are associated with low bone mass in professional horse-racing jockeys. J Bone Miner Metab 2012; 30: 534-542

[24] Dolan E, O'Connor H, McGoldrick A, O'Loughlin G, Lyons D, Warrington G. Nutritional, lifestyle, and weight control practices of professional jockeys. J Sports Sci 2011; 29: 791-799

[25] Wilson G, Drust B, Morton JP, Close GL. Weight-making strategies in professional jockeys: Implications for physical and mental health and well-being. Sports Med 2014; 44: 785-796

[26] Fernandes GS, Parekh SM, Moses J, Fuller C, Scammell B, Batt ME, Zhang W, Doherty M. Prevalence of knee pain, radiographic osteoarthritis and arthroplasty in retired professional footballers compared with men in the general population: A cross-sectional study. Br J Sports Med 2018; 52: 678-683

[27] Losty C, Warrington G, McGoldrick A, Murphy C, Burrows E, Cullen S. Mental health and wellbeing of jockeys. Journal of Human Sport and Exercise 2019; 14: 147-158

[28] King M, Nazareth I, Levy G, Walker C, Morris R, Weich S, Bellon-Saameno JA, Moreno B, Svab I, Rotar D, Rifel J, Maaroos HI, Aluoja A, Kalda R, Neeleman J, Geerlings MI, Xavier M, de Almeida MC, Correa B, Torres-Gonzalez F. Prevalence of common mental disorders in general practice attendees across Europe. Br J Psychiatry 2008; 192: 362-367

[29] Kessler RC, Berglund P, Demler O, Jin R, Merikangas KR, Walters EE. Lifetime prevalence and age-of-onset distributions of DSM-IV disorders in the National Comorbidity Survey Replication. Arch Gen Psychiatry 2005; 62: 593-602

[30] Cosh S, Crabb S, A. L. Elite athletes and retirement: Identity, choice, and agency. Aust J Psychol 2013; 65: 89-97

[31] Guskiewicz KM, Marshall SW, Bailes J, McCrea M, Harding HP Jr., Matthews A, Mihalik JR, Cantu RC. Recurrent concussion and risk of depression in retired professional football players. Med Sci Sports Exerc 2007; 39: 903-909

[32] Caulfield M], Karageorghis Cl. Psychological effects of rapid weight loss and attitudes towards eating among professional jockeys. J Sports Sci 2008; 26: 877-883

[33] Bair M], Robinson RL, Katon W, Kroenke K. Depression and pain comorbidity: A literature review. Arch Intern Med 2003; 163: 2433-2445

[34] Connor Gorber S, Tremblay M, Moher D, Gorber B. A comparison of direct vs. self-report measures for assessing height, weight and body mass index: A systematic review. Obes Rev 2007; 8: 307-326

[35] Dahl AK, Hassing LB, Fransson El, Pedersen NL. Agreement between self-reported and measured height, weight and body mass index in old age-a longitudinal study with 20 years of follow-up. Age Ageing 2010; 39: $445-451$ 